\title{
The application of system dynamics modelling to environmental health decision-making and policy - a scoping review
}

Danielle J. Currie ${ }^{1^{*}}$, Carl Smith ${ }^{2}$ and Paul Jagals ${ }^{3}$

\begin{abstract}
Background: Policy and decision-making processes are routinely challenged by the complex and dynamic nature of environmental health problems. System dynamics modelling has demonstrated considerable value across a number of different fields to help decision-makers understand and predict the dynamic behaviour of complex systems in support the development of effective policy actions. In this scoping review we investigate if, and in what contexts, system dynamics modelling is being used to inform policy or decision-making processes related to environmental health.
\end{abstract}

Methods: Four electronic databases and the grey literature were systematically searched to identify studies that intersect the areas environmental health, system dynamics modelling, and decision-making. Studies identified in the initial screening were further screened for their contextual, methodological and application-related relevancy. Studies deemed 'relevant' or 'highly relevant' according to all three criteria were included in this review. Key themes related to the rationale, impact and limitation of using system dynamics in the context of environmental health decision-making and policy were analysed.

Results: We identified a limited number of relevant studies $(n=15)$, two-thirds of which were conducted between 2011 and 2016. The majority of applications occurred in non-health related sectors $(n=9)$ including transportation, public utilities, water, housing, food, agriculture, and urban and regional planning. Applications were primarily targeted at micro-level (local, community or grassroots) decision-making processes $(n=9)$, with macro-level (national or international) decision-making to a lesser degree. There was significant heterogeneity in the stated rationales for using system dynamics and the intended impact of the system dynamics model on decision-making processes. A series of user-related, technical and application-related limitations and challenges were identified. None of the reported limitations or challenges appeared unique to the application of system dynamics within the context of environmental health problems, but rather to the use of system dynamics in general.

Conclusions: This review reveals that while system dynamics modelling is increasingly being used to inform decision-making related to environmental health, applications are currently limited. Greater application of system dynamics within this context is needed before its benefits and limitations can be fully understood.

Keywords: System dynamics modelling, Environmental health, Decision support systems, Decision-making, Policy, Scoping review

\footnotetext{
* Correspondence: d.currie@uq.edu.au

${ }^{1}$ School of Public Health, The University of Queensland, Herston, Brisbane,

QLD 4006, Australia

Full list of author information is available at the end of the article
} 


\section{Background}

There is growing recognition of the complexity that underlies environmental health problems and their management [1] and with it the need for sound environmental health policy and decision-making that embraces this complexity [2]. To embrace this complexity, managers of environmental health issues must move away from reductionist approaches to decision-making, as environmental health hazards are influenced by a multitude of interacting factors that may not initially appear related [3]. This can result in policy resistance, which is the tendency for policies to be ineffective or have unintended consequences that create new problems or exacerbate the original problem [4]. Examples include the digging of wells in South East Asia to combat diarrhoea caused by poor quality surface water, resulting in the largest exposure in history of a population to arsenic-contaminated groundwater [5], and making dwellings in the United Kingdom more air tight to improve household energy efficiency, resulting in increased indoor exposure to radon [6].

Decision-makers, more than ever, are required to integrate scientific and expert-based evidence into decisionmaking. Complexity can hinder evidence-based decisionmaking by slowing and weakening the ways in which evidence is collected, interpreted and translated into action [7]. Evidence for complex problems can be lacking, limited and ambiguous, and is often presented without links to the broader context for which the evidence is required. Also, the analytical tools currently used to support evidencebased decision making, such as statistical modelling, are limited in their ability to explain causation and the effect of non-linear interactions and feedback on the behaviour of complex systems [8]. Given this, there is a need to provide decision-makers with the tools necessary to understand complex environmental health issues as part of implement more scientific decision-making processes.

System dynamics modelling is a problem-oriented modelling approach pioneered by Jay Forrester in the late 1950's to help corporate managers better understand industrial problems [9]. Since then, its application has expanded to fields ranging from ecology to economics. Examples of its use include modelling the dynamics of the earth's climate [10], healthcare systems [11], the food industry [12] and the military [13]. System dynamics involves causal mapping and the development of computer simulation to understand system behaviour. Policy and scenario options are then systematically tested to answer "what-if" questions [14]. This allows policy-makers to experiment with their decisions before implementation in the real world. This decision-experimentation creates a learning environment in which policy makers gain a better understanding of how the system will respond to their decisions and the potential unintended consequences of decisions.
Conventional problem solving tends to approach complex problems by breaking them into their component parts and examining them separately. System dynamics centres on the idea that problems exist due to the interactions, feedback loops and material and information delays among component parts within a system. System dynamics therefore focuses on the relationships between the parts rather than focusing on separate parts in isolation [15]. System dynamics also draws strongly on the concept of endogeneity, meaning that it seeks to find explanations for system behaviour by understanding the internal structure of a system rather than focusing on factors external to the system [16]. For example, when trying to understand why medical errors still occur in seemingly well-managed hospital settings, the temptation is to blame the problem on individuallevel factors beyond the control of the hospital, such as incompetent or lazy practitioners. An endogenous perspective would take the view that most medical errors are the result of a combination of systemic factors such as the practitioner's patient load, training, medication labelling practices, hours worked, etc. and thus the solution lies within understanding how these factors contribute to medical errors and modifying the system to prevent errors.

In this paper we review the application of system dynamics to the management of environmental health issues. System dynamics has been used to understand the interactions between human health and the environment before, such as zoonotic infections [17], the relationship between air pollution, health and population growth [18], the societal costs and benefits of commuter bicycling [19], the effect of land use and transport policies on health [20] and malaria control [21]. However, many of these applications do not demonstrate how, or if, an understanding of system dynamics can lead to better policy and decision-making. Therefore it remains unclear whether the findings of these previous applications of system dynamics have remained within the confines of academia or if they have been applied to inform real decision-making processes.

\section{Objective}

An increasing number of authors advocate for the use of systems thinking and system dynamics in epidemiology, public health and health service delivery [22-24], but it is unclear to what extent system dynamics has actually been used to inform policy or decision-making processes in environmental health service delivery. The objective of this review was to answer the following question "How is system dynamics being used to inform decisionmaking processes related to environmental health?" To answer this question we conducted a scoping review of the scientific and the grey literature. 


\section{Methods}

We used a scoping review method because the objective of the review was to broadly explore how system dynamics has been used to inform environmental health decision-making processes, as opposed appraising the quality of individual studies. Scoping reviews search a wide range of research and non-research reports to uncover the breath and extent of research and application for a particular topic [25]. The design of this study was guided by the scoping review guidelines developed by Arksey and O'Malley [26] and the recommendations proposed by Levac, et al. [27], but included an additional step where papers where re-screened based on their relevancy to objectives of this review. The result was a five-step process: formulation of an objective, identification of potentially relevant science and grey literature through a systematic search, secondary screening using a framework of relevancy-based criteria to select literature the most suitable for review, recording of relevant key themes emerging from the literature, and reporting of results.

Given the extent of this scoping review, we do not claim that the literature captured is an exhaustive or complete list of the scientific and grey literature on this topic, rather a representative sample of the available literature.

\section{Identifying relevant reports}

A systematic search of the literature in the Pubmed, Embase, Web of Science and Scopus databases was conducted. Following an initial broad search of the literature, and in consultation with a health-science librarian, three conceptual focus areas (search themes) with associated search terms were identified: environmental health, system dynamics, and decision-making. The search terms used in combination included ("environmental health" OR "environment and public health" OR "environment") AND ("systems thinking" OR "systems science" OR "systems approach" OR "systems theory" OR "systems analysis" OR "system dynamics" OR "dynamic systems") AND ("health policy" OR "policy making" OR "decision making" OR "health planning" OR "policy" OR “'decision support system" OR "decision support techniques" OR "environmental policy”). Where available, we used indexing terminology (MeSH and Emtree) that corresponded to the search terms. The search was limited to reports published in English between the years 2000 and 2016. The review was limited to reports published after 2000 to reflect the significant increase in publications related to systems thinking and systems science that has occurred since then [28], as well as the rapidly-evolving nature of the field of environmental health [29].
The same search terms were used in the Google search engine to similarly identify relevant grey literature.

\section{Report selection}

Reports captured though the search of the academic and grey literature were initially screened according to inclusion criteria developed for this review (Table 1).

To ensure that the retained reports would meet the objective of this review, we developed three relevancy criteria (Table 2) to determine the strength of each paper pertaining to the three conceptual focus areas of this review: environmental health, system dynamics and decision-making. This relevancy approach was adopted because the concepts of environmental health and decision-making are broadly-defined concepts that do not lend themselves to specific inclusion criteria. Reports retained during the initial screening process were then screened according to the relevancy criteria. Reports classed as 'somewhat relevant' or 'not relevant' to one or more of the relevancy criteria were excluded from further review.

Reports that were classed 'relevant' or 'highly relevant' for all three relevancy criteria were included in this review. For each retained report, data on the location, sector of application, project objectives, link to health and type of system dynamics analysis techniques used was organised in a Microsoft Excel ${ }^{\odot}$ spreadsheet. Reports were also analysed to identify key themes related to the stated rationales for using system dynamics, the intended impact of system dynamics modelling on decision-making, the targeted scale of decision-making and limitations and challenges associated with system dynamics modelling.

\section{Results}

\section{Search findings}

A total of 5732 unique reports were identified by searching scientific databases (Fig. 1). An additional 84 publications were identified through a search of the grey literature, a search of the reference lists of retained articles, and the 'related articles' or 'cited by' section in the databases. At the end of initial screening using the inclusion criteria, 166 reports were retained. Screening according to the relevancy criteria left 15 reports for final review.

Table 1 Inclusion criteria for initial screening process

\begin{tabular}{ll}
\hline Inclusion criteria & - \\
& envimary focus of study is examining an \\
- & Reports on the original application of \\
& system dynamics methods (is not a \\
& review paper, position paper or commentary) \\
- & Demonstrates a link between system \\
& dynamics and a population-level policy or \\
& decision-making process \\
- Published after January 1, 2000 \\
- Written in English \\
\hline
\end{tabular}


Table 2 Relevancy Criteria

RC 1 - Subject / content relevancy - Area of environmental health service delivery

The report's primary focus is related to the assessment and control of environmental factors: in the goal of the investigation.

Highly Relevant - that directly contribute to the creation of health-supportive environments, but where the protection or promotion of human health and wellbeing is directly included

Relevant - that directly contribute to the creation of health-supportive environments, but where the protection or promotion of human health and wellbeing is not directly included in the goal of the investigation.

Somewhat Relevant - that indirectly contribute to the creation of health-supportive environments, and where the protection or promotion of human health and wellbeing is not directly included in the goal of the investigation.

Not Relevant - that do not affect human health or the creation of health-supportive environments.

RC 2 - Methodological Relevancy - Use of system dynamics to address an environmental health problem

The report describes the use of system dynamics to examine the assessment or control of one or more environmental factors:
Highly Relevant - directly in relation to the impact that the factor can potentially have on population health.

Relevant - indirectly in relation to the impact that the factor(s) can potentially have on human health. This includes reports that include environmental health hazard or risk factors in the system dynamics modelling without directly addressing their impact on population health.

Somewhat Relevant - which can reasonably be assumed is done, at least in part, for the protection of population health or the creation of health-supportive environments, but does not directly or indirectly examine the impact that the factor can potentially have on population health.

Not Relevant - not in relation to the impact that the factor can potentially have on human health.

RC 3 - Application Relevancy - Application in public decision-making
The report outlines the use of system dynamics modelling in a way that is intentionally intended:

Highly Relevant - to inform a specific policy or decision-making processes including specifying how the modelling process or model findings we used to inform the policy or decision-making process.

Relevant - to inform a specific policy or decision-making processes without specifying how the modelling process or model findings we used to inform the policy or decision-making process.

Somewhat Relevant - to inform non-specific policy or decision-making processes, without specifying if or how the modelling process or model findings were used to inform a policy or decision-making process.

Not Relevant - not in a way that is intentionally intended to inform policy or decision-making processes

\section{General characteristics}

The general characteristics of the 15 reviewed reports are outlined in Table 3. Of these, $47 \%(n=7)$ of the studies were conducted in the United States of America. The rest were conducted in the United Kingdom $(n=2)$, Canada $(n=1)$, New Zealand $(\mathrm{n}=1)$, Taiwan $(\mathrm{n}=1)$, Colombia $(\mathrm{n}=1)$, Bolivia $(\mathrm{n}=1)$ and in both Ghana and Ethiopia $(n=1)$. The majority of the studies $(67 \%)$ were conducted within the last 5 years (2011-2016), which suggests recent and increasing interest that systems science that has been identified in other areas of the published health literature [28].

The reports used system dynamics to inform decisionmaking within, and across, a number of different sectors, and all relevant to environmental health. The greatest number came from within the health sector $(n=6)$, with the remaining coming from the transport sector $(n=2)$, the public utilities sector $(n=1)$, the water sector $(n=$ $1)$, the housing sector $(n=1)$, food sector $(n=1)$, the agricultural sector $(\mathrm{n}=1)$, and the urban and regional planning sector $(\mathrm{n}=1)$. Additionally, one report was multi-sectoral within both the urban and regional planning and the transportation sector.

The majority of reports $(n=11)$ explicitly dealt with the relationship between environment and human health, using system dynamics to map and/or model system structures and behaviours that govern environmental conditions and their effect on human health. The remainder of reports $(n=4)$ had an inferred link to health. In these cases, structural and behavioural links between environmental conditions and environmental health hazards, such as air pollution and water pollution, were modelled. These models were broadly focused on creating and testing policies whose multiple objectives included the protection of human health or the creation of health-supportive environments.

The majority of reports $(n=13)$ used system dynamics to conduct systemic analysis of a problem and then used simulation and policy analysis to model and test the outcome of various policies. The remaining two reports used system dynamics in only a qualitative way, using causal loop diagrams to qualitatively analyse the relationship between system structure and problem behaviours.

\section{Stated rationales for using system dynamics}

Eleven of the publications stated one or more rationales for using system dynamics methods. Many of the stated rationale focused on the technical capabilities of system dynamics models, including their ability to identify and account for sources of uncertainty in the understanding of causal relationships [30,31], account for long timedelays between action and effect [30], reveal the endogenous sources of system behaviour [32, 33], and link the dynamic effects of policy actions to system structure and behaviour $[31,34,35]$. Others focused on the predictive capabilities of system dynamics models including their ability to integrating multiple types of information 


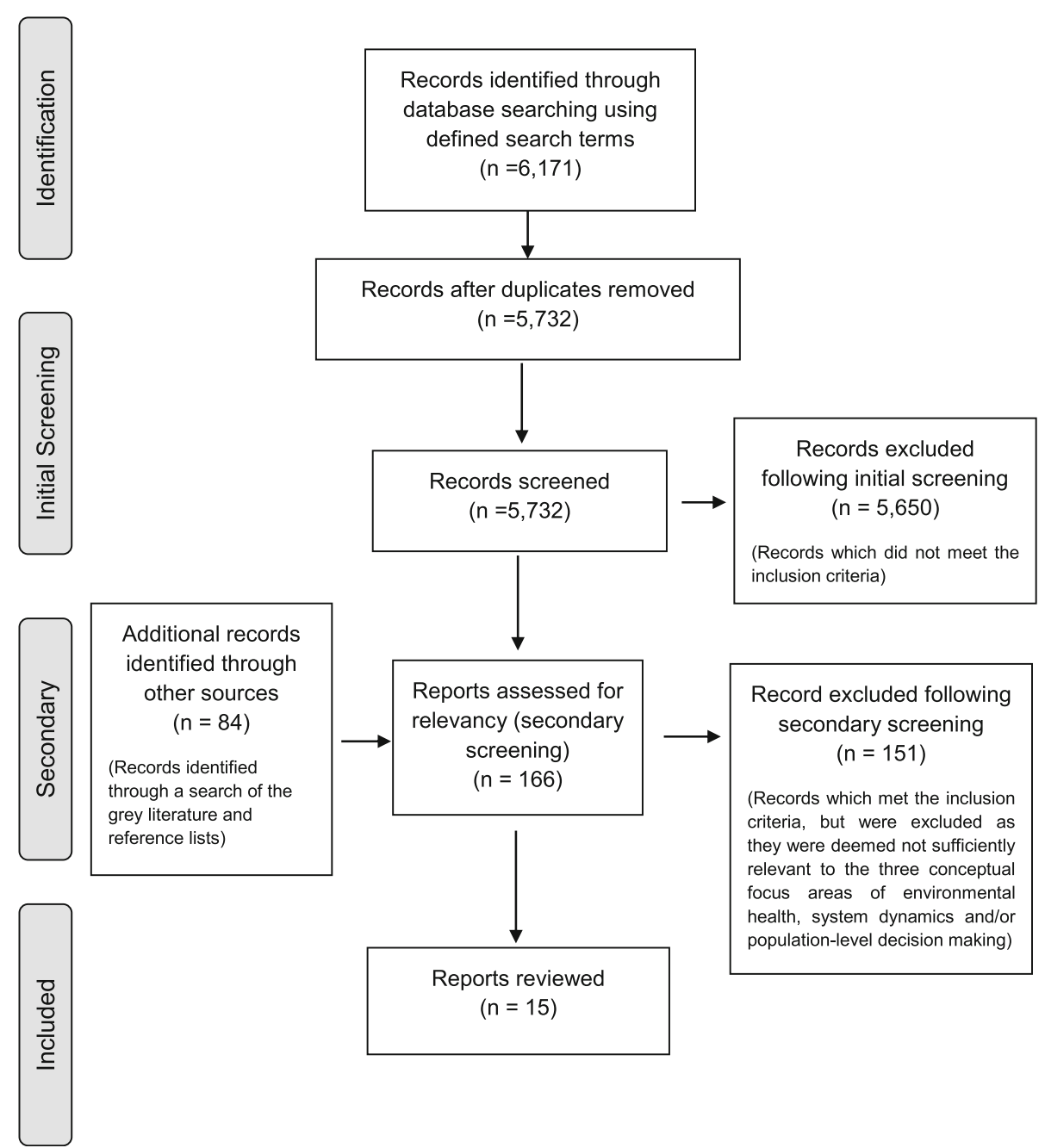

Fig. 1 Selection process and results

into policy analysis [36, 37], assess program and policy intervention trade-offs [38, 39], and explore the effects of proposed policies over a chosen time scale [35, 38]. Lastly, a number of the publications also included process-related factors in their rationale for using system dynamics modelling, including its strength at making sense of the complexity of the problem [33, 38], and its potential to facilitate inter-sectoral and stakeholder engagement [33, 37-39].

\section{Intended impact of system dynamics modelling on decision-making}

The intended users of the outcomes of system dynamics modelling fell into two categories: the decision- or policy-makers themselves, and the stakeholders affected by or involved in decision-making processes (Table 4).

One of the key uses of system dynamics identified in the reports was decision support for making policies and decisions. In these instances, the goal of the system dynamics modelling process was to compare the results of various policy scenarios to inform strategic policy decisions. Some of the models were designed to provide decision-support for a specific project or policy issue, such as the model designed in Kolling et al. [40], which was used to explore the community-level impacts and viability of a light rail project. Other models were intended for integration into existing or future decisionmaking processes, such as the model described in Chen et al. [41], which was designed for the model to be integrated directly into the analysis and review phases of a county-level urban planning process.

System dynamics models were also used to influence the way that decision- or policy-makers approach a particular topic or policy issue. In several of these reports the authors describe the modelling process itself as having significant benefit, irrespective of the results the model produced. Stave and Dwyer [42] reported that the collaborative process of creating the system dynamics 
Table 3 General characteristics of selected studies

\begin{tabular}{|c|c|c|c|c|c|}
\hline Author, year & Location & Sector & Study/Project Objective & Health Link & $\begin{array}{l}\text { Use of System } \\
\text { Dynamics }\end{array}$ \\
\hline Brennan, et al., 2015 & United States of America & Health & $\begin{array}{l}\text { identify trends and underlying feedback } \\
\text { systems hypothesized by stakeholders } \\
\text { as driving local change in health } \\
\text { behaviours and obesity }\end{array}$ & Explicit & Systemic analysis \\
\hline Chen, et al., 2005 & Taiwan & $\begin{array}{l}\text { Urban and } \\
\text { Regional Planning }\end{array}$ & $\begin{array}{l}\text { develop a dynamic strategy planning } \\
\text { theory and system for sustainable river } \\
\text { basin land use management }\end{array}$ & Inferred & $\begin{array}{l}\text { Systemic analysis, } \\
\text { simulation and } \\
\text { policy analysis }\end{array}$ \\
\hline Feola, et al., 2012 & Colombia & Agriculture & $\begin{array}{l}\text { uncover the social processes underlying } \\
\text { the misuse of personal protective } \\
\text { equipment, and support the identification } \\
\text { and evaluation of intervention strategies }\end{array}$ & Explicit & $\begin{array}{l}\text { Systemic analysis, } \\
\text { simulation and } \\
\text { policy analysis }\end{array}$ \\
\hline Kenealy, et al., 2012, & New Zealand & Health & $\begin{array}{l}\text { assess the usefulness of a national and } \\
\text { a local system dynamics model of } \\
\text { cardiovascular disease to planning and } \\
\text { funding decision makers }\end{array}$ & Explicit & $\begin{array}{l}\text { Systemic analysis, } \\
\text { simulation and } \\
\text { policy analysis }\end{array}$ \\
\hline Kolling, et al., 2016 & United States of America & Transportation & $\begin{array}{l}\text { design an approach that uses dynamics } \\
\text { systems modelling to explore the interplay } \\
\text { among actions and decisions that lead to } \\
\text { healthier and more sustainable communities }\end{array}$ & Explicit & $\begin{array}{l}\text { Systemic analysis, } \\
\text { simulation and } \\
\text { policy analysis }\end{array}$ \\
\hline Lane, 2014 & United Kingdom & Food & $\begin{array}{l}\text { investigate the relative significance of the } \\
\text { foodborne transmission mechanisms on } \\
\text { the scale of norovirus outbreaks and } \\
\text { identify intervention leverage points }\end{array}$ & Explicit & $\begin{array}{l}\text { Systemic analysis, } \\
\text { simulation and } \\
\text { policy analysis }\end{array}$ \\
\hline Loyo et al., 2013 & United States of America & Health & $\begin{array}{l}\text { align stakeholders to develop a } \\
\text { comprehensive strategy for reducing } \\
\text { chronic diseases and related costs }\end{array}$ & Explicit & $\begin{array}{l}\text { Systemic analysis, } \\
\text { simulation and } \\
\text { policy analysis }\end{array}$ \\
\hline Macmillan et al., 2016 & United Kingdom & Housing & $\begin{array}{l}\text { develop a collaborative understanding of } \\
\text { the complex system linking housing, } \\
\text { energy and wellbeing }\end{array}$ & Explicit & Systemic analysis \\
\hline $\begin{array}{l}\text { Mahamoud, Roche } \\
\text { and Homer, } 2013\end{array}$ & Canada & Health & $\begin{array}{l}\text { investigate causal pathways between } \\
\text { population health risk factors and health } \\
\text { outcomes and identify policy options } \\
\text { related to the social determinants of health }\end{array}$ & Explicit & $\begin{array}{l}\text { Systemic analysis, } \\
\text { simulation and } \\
\text { policy analysis }\end{array}$ \\
\hline Newman, et al., 2003 & Bolivia & Health & $\begin{array}{l}\text { develop models that explicitly link policy } \\
\text { actions with results in the context of } \\
\text { malaria control }\end{array}$ & Explicit & $\begin{array}{l}\text { Systemic analysis, } \\
\text { simulation and } \\
\text { policy analysis }\end{array}$ \\
\hline Olabisi, et al. 2012 & United States of America & Health & $\begin{array}{l}\text { develop a tool that is useful for local } \\
\text { decision-makers responding to extreme } \\
\text { heat events }\end{array}$ & Explicit & $\begin{array}{l}\text { Systemic analysis, } \\
\text { simulation and } \\
\text { policy analysis }\end{array}$ \\
\hline Pasqualini et al., 2006 & United States of America & Public Utilities & $\begin{array}{l}\text { investigate the consequences of } \\
\text { disruptions in potable water distribution } \\
\text { systems }\end{array}$ & Explicit & $\begin{array}{l}\text { Systemic analysis } \\
\text { and simulation }\end{array}$ \\
\hline Raschid-Sally, et al., 2013 & Ghana, Ethiopia & Water & $\begin{array}{l}\text { examine the impacts of climatic and } \\
\text { demographic changes on urban water } \\
\text { resources management and develop a } \\
\text { strategic action plan based on improved } \\
\text { water resource management }\end{array}$ & Inferred & $\begin{array}{l}\text { Systemic analysis, } \\
\text { simulation and } \\
\text { policy analysis }\end{array}$ \\
\hline Stave and Dwyer, 2006 & United States of America & $\begin{array}{l}\text { Urban and } \\
\text { Regional Planning, } \\
\text { Transportation }\end{array}$ & $\begin{array}{l}\text { improve the ability of local agencies and } \\
\text { government entities to integrate land use, } \\
\text { air quality and transportation planning }\end{array}$ & Inferred & $\begin{array}{l}\text { Systemic analysis, } \\
\text { simulation and } \\
\text { policy analysis }\end{array}$ \\
\hline Stave, 2002 & United States of America & Transportation & $\begin{array}{l}\text { develop policy recommendations to } \\
\text { address traffic congestion and regional air } \\
\text { quality problems }\end{array}$ & Inferred & $\begin{array}{l}\text { Systemic analysis, } \\
\text { simulation and } \\
\text { policy analysis }\end{array}$ \\
\hline
\end{tabular}

model provided a means for integrating traditionally separate land use, transportation and air quality planning processes. This integration compelled decision-makers in each sector to shift their perspective away from focusing solely on their particular area of practice to viewing the system as a whole.

This review found that applications of system dynamics to inform or influence environmental health decision- 
Table 4 Intended impact of system dynamics on decisionmaking processes

\begin{tabular}{|c|c|}
\hline Intended impact & $\begin{array}{l}\text { Number of studies } \\
\text { [reference] }\end{array}$ \\
\hline \multicolumn{2}{|l|}{ Direct decision-maker decision-support } \\
\hline $\begin{array}{l}\text { Providing specific policy analysis related } \\
\text { to an existing or anticipated policy issue }\end{array}$ & $4[31,32,40,43]$ \\
\hline $\begin{array}{l}\text { Providing continuous use as a tool integrated } \\
\text { into existing or future decision-making processes }\end{array}$ & $3[41,42,53]$ \\
\hline \multicolumn{2}{|l|}{ Indirect decision-maker decision-support } \\
\hline $\begin{array}{l}\text { Educating decision-makers about system } \\
\text { structure and behaviour }\end{array}$ & $5[30,34,36,40,42]$ \\
\hline $\begin{array}{l}\text { Confirming or challenging decision-makers' } \\
\text { beliefs or understanding of the problem }\end{array}$ & $3[34,36,42]$ \\
\hline $\begin{array}{l}\text { Facilitating inter-sectoral planning and } \\
\text { decision-making processes }\end{array}$ & $4[30,36,40,42]$ \\
\hline supporting advocacy for a particular decision & $2[30,42]$ \\
\hline \multicolumn{2}{|l|}{ Stakeholder engagement and decision-support } \\
\hline $\begin{array}{l}\text { Helping stakeholders and decision-makers } \\
\text { develop and articulate a shared understanding } \\
\text { of the problem }\end{array}$ & $7[33,35-40]$ \\
\hline $\begin{array}{l}\text { Facilitating the inclusion of stakeholder } \\
\text { perspective in policy analysis process }\end{array}$ & $6[35-40]$ \\
\hline $\begin{array}{l}\text { Communicating information about the } \\
\text { problem and policy options to stakeholder }\end{array}$ & $1[36]$ \\
\hline Serving to as a catalyst for stakeholder action & $1[39]$ \\
\hline $\begin{array}{l}\text { Promoting stakeholder buy-in to policy } \\
\text { recommendations }\end{array}$ & $2[33,40]$ \\
\hline
\end{tabular}

making extended beyond those targeted directly at informing decision-makers, and also included processes targeted at engaging stakeholders in decision-making processes. For example, Stave [37] used system dynamics modelling as a means to integrate stakeholder feedback into the decision-making process, with the idea that if stakeholders are involved in making strategic decisions, they are more likely to ultimately help implement the outcome of those decisions.

\section{Targeted scale of decision-making}

The review also showed that system dynamics was used to inform policy and decision making processes at two distinct levels: macro-level decision making (national or international) and the micro-level (local, community or grassroots).

System dynamics was used to exclusively support micro-level decision-making processes in over half of the studies $(n=9)$. Macro-level policy and decision-making was the primary focus of four studies targeted at decisionmaking in federal/national government departments.

Two studies used system dynamics to influence decision-making at both levels. The URAdapt project [43] targeted decision-making processes and policy actors at both the local and national level because the urban water supply systems in Addis Ababa and Accra fell under both the jurisdiction of local municipalities and national-level government departments. System dynamics was used in the Durham-Orange Light Rail Project in Durham, North Carolina [40] to inform and engage both federal and local decision-makers because components of the project fell under mandates at both levels.

No studies were identified where decision-making or policy at the meso-level (regional, provincial or state level) was the target.

\section{Limitations and challenges associated with using system dynamics for environmental health decision-making}

Twelve reports referred to limitations and challenges associated with using system dynamics modelling within the context of the problem being addressed. For the purpose of this review, only limitations and challenges related to the process of system dynamics modelling or the overall functionality of system dynamics models were analysed. Limitations for the purposes of this review were grouped into three categories: limitations related to those involved in the modelling process, technical limitations of system dynamics, and limitations related to the application of the results to decisionmaking (Table 5). Note that none of the limitations or challenges identified by the authors appeared to be related specifically to the application of system dynamics to environmental health problems, but rather to the application of system dynamics in general.

\section{Discussion}

To our knowledge, a review of the applications of system dynamics to environmental health decision-making has not been previously conducted. Our findings suggest that the applications of system dynamics to environmental health decision-making is limited given the paucity of reporting, however the applications that were found vary across many different sectors. Our review further suggested that the use of system dynamics in this context represents an emerging field of research and practice, with the number of studies published increasing considerably in the last five years. While many of the reported studies occurred within the public health or health service sectors, there were a variety of non-health-specific sectors using system dynamics to model both environmental and health factors.

The 1986 Ottawa Charter for Health Promotion recognised that the promotion of health cannot be done by the health-sector alone, and that the success of healthpromoting activities, such as those occurring within the field of environmental health, depend on the successful collaboration and support of many different sectors [44]. Our review strongly suggests that system dynamics can be used as a method to facilitate the integration of 
Table 5 Limitations and challenges associated with system dynamics modelling

\begin{tabular}{|c|c|}
\hline Limitation/Challenge & $\begin{array}{l}\text { Number of studies } \\
\text { [reference] }\end{array}$ \\
\hline \multicolumn{2}{|l|}{ User-related } \\
\hline $\begin{array}{l}\text { Participants needed subject-matter knowledge and } \\
\text { familiarity with system dynamics to meaningfully } \\
\text { participate in the modelling process }\end{array}$ & $3[33,39,40]$ \\
\hline $\begin{array}{l}\text { Those using the model but not closely involved } \\
\text { in the model-making process struggled to } \\
\text { understand and trust the model and its results }\end{array}$ & $2[30,36]$ \\
\hline $\begin{array}{l}\text { Significant commitment and time investment } \\
\text { needed by participants }\end{array}$ & $1[37]$ \\
\hline $\begin{array}{l}\text { Complexity of the system dynamics model may } \\
\text { make it difficult for users to understand the } \\
\text { details of the model and this may increase the } \\
\text { perception that the problem is so complex that } \\
\text { it is not feasible to tackle }\end{array}$ & $2[33,36]$ \\
\hline $\begin{array}{l}\text { Potential unwillingness of participants to have } \\
\text { their perception / beliefs about the problem } \\
\text { (otherwise known as mental models) challenged }\end{array}$ & $1[37]$ \\
\hline \multicolumn{2}{|l|}{ Technical } \\
\hline $\begin{array}{l}\text { The inclusion of subjective variables whose } \\
\text { behaviour may be influenced by interpretation- } \\
\text { bias }\end{array}$ & $1[38]$ \\
\hline $\begin{array}{l}\text { The inherent uncertainty regarding variables and } \\
\text { causal structures of complex problems, resulting } \\
\text { key variables being unintentionally omitted from } \\
\text { the model }\end{array}$ & $1[32]$ \\
\hline $\begin{array}{l}\text { The inclusion of parameters whose values are } \\
\text { unknown and cannot reasonably be estimated }\end{array}$ & $1[32]$ \\
\hline $\begin{array}{l}\text { The creation of fully endogenous models of large } \\
\text { and complex problems can result in huge 'data } \\
\text { hungry' models }\end{array}$ & $1[32]$ \\
\hline $\begin{array}{l}\text { The accuracy and comprehensiveness of the } \\
\text { model depends heavily on the inclusion of an } \\
\text { appropriate mix of stakeholders }\end{array}$ & $1[35]$ \\
\hline $\begin{array}{l}\text { the complexity of the end product may result in } \\
\text { end-users requiring a model guide in order to } \\
\text { effectively use the model }\end{array}$ & $1[36]$ \\
\hline $\begin{array}{l}\text { The model's output did not provide specific } \\
\text { directions for end-users, but rather showed } \\
\text { possible future trends and relative magnitudes } \\
\text { of impact }\end{array}$ & $2[38,40]$ \\
\hline \multicolumn{2}{|l|}{ Application-related } \\
\hline $\begin{array}{l}\text { System-wide changes are difficult to implement } \\
\text { given the often 'siloed' nature of public } \\
\text { governance structures }\end{array}$ & $2[41,43]$ \\
\hline $\begin{array}{l}\text { There is potential for incompatibility between the } \\
\text { timescale of political and public decision-making } \\
\text { and system dynamics model-building, which } \\
\text { results in rushed and over-simplified model }\end{array}$ & $1[37]$ \\
\hline $\begin{array}{l}\text { Obtaining decision-maker buy-in is difficult due to } \\
\text { the disparity that exists between system } \\
\text { dynamics' goal of identifying sources of } \\
\text { long-term success, and political processes which } \\
\text { focuses primarily on short-term goals and outcomes }\end{array}$ & $1[37]$ \\
\hline
\end{tabular}

health into policy and decision-making processes in non-health sectors.

System dynamics not only provides direct decisionsupport for policy analysis, but also provides a means for understanding problems, which in turn informs the way decisions-makers navigate complex decision-making processes. This is consistent with the way in which system dynamics has been used to address complex problems in other fields such as health policy [45], social care [46], strategic management [47], and transportation [48].

System dynamics has been used to inform decisionmaking at either the micro or macro-level, with limited application targeted at decision-making across multiple levels. While this is potentially due to disconnects between decision-making processes at the micro- and macro-level, it does point to a potential missed opportunity. Complex environmental health problems do not respect jurisdictional boundaries, and can rarely be addressed at only the local or national level. While likely not possible in all situations, the URAdapt project outlined in Raschid-Sally, et al. [43] demonstrates the potential for system dynamics to be used to address environmental health problems at multiple decisionmaking levels.

None of the reports included in this review spoke of the effectiveness of the policies or decisions that resulted from the use of system dynamics. While this is not surprising given the recentness of their publication and the time delays between the implementation of decisions and their effects, it does indicate a gap in the literature. Evaluations of the effectiveness of decisions or policies developed based on system dynamics models will help researchers and decision-makers evaluate the merit of using system dynamics to address complex problems.

Multiple limitations and challenges associated with the application of system dynamics were discussed in the reports reviewed, but none were specifically directed at its feasibility for application to environmental health problems. Many of the limitations, such as the level of complexity of the models and a lack of participant openness to challenge their mental models, were consistent with applications of system dynamics in other fields $[49,50]$.

It is worth noting that some of the identified limitations, such as potential unwillingness of participants to have their mental models challenged, are not necessarily limitations of system dynamics itself, but rather a limitation of the way it is used. While using system dynamics in a participatory learning process increases the chances that participants and stakeholders will critically reflect on their own mental models, there are no guarantees that system dynamics, or any other policy analysis process, can change deeply-held views and positions. These issues are not insurmountable, but require further research and action from both the system dynamics 
scientists and practitioner community and the wider policy and governance communities. As systems approaches become more widespread and integrated into the way current and future decision-makers think about complex problems, the greater the chance that tools like system dynamics will find a receptive audience.

The number of studies that met the inclusion criteria but were ultimately excluded from the review suggests a missing link when it comes to the application of system dynamics to environmental health decision-making. For instance, reports by McClure et al. [20] that examined the relationships among transportation, economic development, land use, and population health; and by Pedercini, et al. [21] that examined the costs and benefits of various malaria control interventions, demonstrated interesting and novel applications of system dynamics in environmental health, but did not link the outcomes of their system dynamics models to a decision-making process. This suggests a gap between basic and applied system dynamics in environmental health and decisionmaking and policy. The water security model reported by El Sawah et al. [51] and the waste management model reported by Stave's [52] suggest how system dynamics could inform decision-making within the field of environmental health, but these applications lacked a health or health hazard component in their model. This also reflects a disconnect between the fields of environmental management and human health. System dynamics does have significant potential to bridge the gap between environmental management and human health, however this needs further demonstration.

\section{Limitations of the review}

This review has several limitations that must be recognised when interpreting the results. First, it identified and summarized only 15 publications, all of which were varied in their rationale and scope. This heterogeneity suggests that while key common elements of the studies could be identified, the complexity of the individual studies were not fully captured. Second, the limited number of reports identified prevents a comprehensive assessment of the benefits and limitations of applying system dynamics to environmental health issues. More applications of system dynamics in this context is called for. Third, the multi-disciplinary nature of environmental health may have caused us to miss some relevant reports. For example, work occurring in sectors such as environmental management, waste management and urban planning - although often not so intended - will directly or indirectly influence human health. It is possible that some authors may not have labelled their work as being related to 'environmental health', making it difficult to capture it in reviews such as this one. Similarly, authors describing applications of system dynamics modelling may have used different terminology to describe their modelling approach, which would have caused their work to be missed by this scoping review. Finally, this review relied on reports being in the public domain. While a systematic search of the scientific and grey literature is likely to capture most reports originating from academia, it is likely that there are reports based on system dynamics applications that have not been published.

\section{Conclusion}

In a world of rapidly changing environments, environmental health decisions and policies must be made regardless of the complexity of environmental health problems and significant uncertainties about the future. It is crucial that we move past discussing the general merits of a systems approach to addressing environmental health problems, to determining how best to apply systems tools and methods to existing environmental health problems.

Our review suggests that system dynamics is being applied sparingly, but increasingly within the field of environmental health. The method has significant potential when it comes to assisting decision-makers understand and analyse complex environmental health issues, as well predict the outcomes environmental health decisions and policies. System dynamics is currently being used in multiple different sectors to provide direct and indirect decision-support for population health policy and decision-making processes. Despite this, the contribution of system dynamics to environmental health policy remains limited. Current decision-making and governance structures in many public organisations are not designed to integrate the multi-sectoral policy advice that system dynamics can provide. Therefore, the full potential of system dynamics to change the way in which environmental health problems are managed cannot be realised unless the decision-making and governance structures of public organisations are collaborative and coordinated.

\section{Acknowledgements}

Not applicable.

\section{Funding}

This research did not receive any specific grant from funding agencies in the public, commercial, or not-for-profit sectors.

\section{Availability of data and materials}

The dataset created and analysed during the current study is available from the corresponding author on reasonable request.

\section{Authors' contributions}

DJC conducted the literature search, reviewed the articles, conducted the analyses, and drafted the manuscript. CS and PJ contributed to the interpretation of data, and were involved in the drafting and critical revision of the manuscript. All authors read and approved the final manuscript. 


\section{Ethics approval and consent to participate}

Not applicable.

\section{Consent for publication}

Not applicable.

\section{Competing interests}

The authors declare that they have no competing interests.

\section{Publisher's Note}

Springer Nature remains neutral with regard to jurisdictional claims in published maps and institutional affiliations.

\section{Author details}

'School of Public Health, The University of Queensland, Herston, Brisbane, QLD 4006, Australia. ${ }^{2}$ School of Business, The University of Queensland, St. Lucia, Brisbane, QLD 4072, Australia. ${ }^{3}$ Child Health Research Centre, The University of Queensland, South Brisbane, QLD 4101, Australia.

\section{Received: 20 January 2017 Accepted: 14 March 2018}

Published online: 27 March 2018

\section{References}

1. Keune H. Critical complexity in environmental health practice: simplify and complexify. Environmental health : a global access science source. 2012, 11 Suppl;1:S19.

2. Tarkowski SM. Environmental health research in Europe: bibliometric analysis. Eur J Pub Health. 2007;17(Suppl 1):14-8.

3. Kreuter MW, De Rosa C, Howze EH, Baldwin GT: Understanding wicked problems: a key to advancing environmental health promotion. Health education \& behavior : the official publication of the Society for Public Health Education 2004, 31(4):441-454

4. Forrester JW: Urban dynamics, vol. 114: mlt press Cambridge; 1969.

5. Smith AH, Lingas EO, Rahman M. Contamination of drinking-water by arsenic in Bangladesh: a public health emergency. Bull World Health Organ. 2000;78(9):1093-103.

6. Milner J, Shrubsole C, Das P, Jones B, Ridley I, Chalabi Z, Hamilton I, Armstrong B, Davies M, Wilkinson P. Home energy efficiency and radon related risk of lung cancer: modelling study. BMJ. 2014;348

7. Sterman JD. Learning from evidence in a complex world. Am J Public Health. 2006;96(3):505-14.

8. Atkinson J-A, Page A, Wells R, Milat A, Wilson A. A modelling tool for policy analysis to support the design of efficient and effective policy responses for complex public health problems. Implement Sci. 2015;10(1):1-9.

9. Forrester JW. Industrial dynamics - a major breakthrough for decision makers. Harv Bus Rev. 1958;36(4):37-66.

10. Sterman JD, Fiddaman T, Franck T, Jones A, McCauley S, Rice P, Sawin E, Siegel L. Management flight simulators to support climate negotiations. Environ Model Softw. 2013;44:122-35.

11. Dangerfield BC. System dynamics applications to European health care issues. J Oper Res Soc. 1999;50(4):345-53.

12. Minegishi S, Thiel D. System dynamics modeling and simulation of a particular food supply chain. Simulation Practice and Theory. 2000;8(5): 321-39.

13. Bakken BT, Gilljam M. Dynamic intuition in military command and control: why it is important, and how it should be developed. Cogn Tech Work. 2003;5(3):197-205.

14. Homer JB, Hirsch GB. System dynamics modeling for public health: background and opportunities. Am J Public Health. 2006;96(3):452-8.

15. Bosch O, Maani K, Smith C. Systems thinking - language of complexity for scientists and managers. In: Improving the triple bottom line returns from small-scale forestry: 18-21 June 2007. Ormoc: the Philippines; 2007.

16. Sterman JD. Business dynamics: systems thinking and modeling for a complex world, vol. 19: Irwin. Boston: McGraw-Hill; 2000.

17. Cox LA Jr, Ricci PF. Causal regulations vs. political will: why human zoonotic infections increase despite precautionary bans on animal antibiotics. Environ Int. 2008;34(4):459-75.

18. Shahgholian K. A Dynamic Model of air pollution, health, and population growth using system dynamics: a study on Tehran-Iran (with computer simulation by the software Vensim). World Acad Sci Eng Technol. 2009; 59:245-52.
19. Macmillan A, Connor J, Witten K, Kearns R, Rees D, Woodward A. The societal costs and benefits of commuter bicycling: simulating the effects of specific policies using system dynamics modeling. Environ Health Perspect. 2014:122(4):335-44.

20. McClure RJ, Adriazola-Steil C, Mulvihill C, Fitzharris M, Salmon P, Bonnington $\mathrm{CP}$, Stevenson M. Simulating the dynamic effect of land use and transport policies on the health of populations. Am J Public Health. 2015;105(Suppl 2): S223-9.

21. Pedercini M, Movilla Blanco S, Kopainsky B. Application of the malaria management model to the analysis of costs and benefits of DDT versus non-DDT malaria control. PLoS One. 2011;6(11):e27771.

22. Galea S, Riddle M, Kaplan GA. Causal thinking and complex system approaches in epidemiology. Int J Epidemiol. 2010;39(1):97-106.

23. Luke DA, Stamatakis KA. Systems science methods in public health: dynamics, networks, and agents. Annu Rev Public Health. 2012;33:357-76.

24. Diez Roux AV. Complex systems thinking and current impasses in health disparities research. Am J Public Health. 2011;101(9):1627-34.

25. Peters MD, Godfrey CM, Khalil H, Mclnerney P, Parker D, Soares CB. Guidance for conducting systematic scoping reviews. International journal of evidence-based healthcare. 2015;13(3):141-6.

26. Arksey H, O'Malley L. Scoping studies: towards a methodological framework. Int J Soc Res Methodol. 2005;8(1):19-32.

27. Levac D, Colquhoun H, O'Brien KK. Scoping studies: advancing the methodology. Implement Sci. 2010;5:69.

28. Adam T. Advancing the application of systems thinking in health. Health Research Policy and Systems. 2014;12(1):1-5

29. Birnbaum LS, Jung P. Evolution in environmental health: incorporating the infectious disease paradigm. Environ Health Perspect. 2010;118(8): 327-8.

30. Kenealy T, Rees D, Sheridan N, Moffitt A, Tibby S, Homer J. A 'whole of system' approach to compare options for CVD interventions in counties Manukau. Aust N Z J Public Health. 2012;36(3):263-8.

31. Newman J, Martin L, Velasco MA, Fantini A-M: A system dynamics approach to monitoring and evaluation at the country level: An Application to the Evaluation of Malaria-Control Programs in Bolivia. In: 5th Biennial World Bank Conference on Evaluation and Development: 15-16 July 2003; Washington DC: World Bank; 2003.

32. Lane D. Modelling the foodborne transmission mechanisms for norovirus. London: Food Standards Agency; 2014.

33. Brennan LK, Sabounchi NS, Kemner AL, Hovmand P. Systems thinking in 49 communities related to healthy eating, active living, and childhood obesity. Journal of public health management and practice : JPHMP. 2015;21(Suppl 3):S55-69.

34. Feola G, Gallati JA, Binder CR. Exploring behavioural change through an agent-oriented system dynamics model: the use of personal protective equipment among pesticide applicators in Colombia. Syst Dyn Rev. 2012; 28(1):69-93.

35. Macmillan A, Davies M, Shrubsole C, Luxford N, May N, Chiu LF, Trutnevyte E, Bobrova Y, Chalabi Z. Integrated decision-making about housing, energy and wellbeing: a qualitative system dynamics model. Environ Health. 2016; 15(1):23-34.

36. Olabisi LS, Levine R, Cameron L, Beaulac M, Wahl R, Blythe S. A modeling framework for informing decision maker response to extreme heat events in Michigan under climate change. In: Brown DB, editor. 2011 project reports. D; Briley, L: Great Lakes Integrated Sciences and Assessments (GLISA) Center; 2012

37. Stave KA. Using system dynamics to improve public participation in environmental decisions. Syst Dyn Rev. 2002;18(2):139-67.

38. Mahamoud A, Roche B, Homer J. Modelling the social determinants of health and simulating short-term and long-term intervention impacts for the City of Toronto, Canada. Soc Sci Med. 1982;2013(93):247-55.

39. Loyo HK, Batcher C, Wile K, Huang P, Orenstein D, Milstein B. From model to action: using a system dynamics model of chronic disease risks to align community action. Health Promot Pract. 2013;14(1):53-61.

40. Kolling J, Cox L, Flanders N, Proctor A, Tanners N, Bassi A, Araujo R. A system dynamics model for integrated decision making: the DurhamOrange light rail project. In. Washington, DC: United States Environmental Protection Agency; 2016.

41. Chen $\mathrm{CH}$, Liu WL, Liaw SL, Yu CH. Development of a dynamic strategy planning theory and system for Sustainable River basin land use management. Sci Total Environ. 2005;346(1-3):17-37. 
42. Stave KA, Dwyer M: Lessons from LUTAQ: Building systems thinking capacity into land use, transportation, and air quality planning in Las Vegas, Nevada In: 24th International Conference of the System Dynamics Society: 23-27 July 2006. Nijmegen; 2006.

43. Raschid-Sally L, Moges S, Sahilu G, Bayrau A, Amisigo B, Akoto-Danso EK. Managing water at the urban-rural Interface: the key to climate change resilient cities (URAdapt). International Water Management Institute; 2013.

44. World Health Organization, Health and Welfare Canada, Canadian Public Health Association: Ottawa Charter for Health Promotion: An international conference on health promotion - the move towards a new public health, Nov. 17-21. Ottawa: World Health Organization; 1986.

45. Atkinson J-A, Wells R, Page A, Dominello A, Haines M, Wilson A. Applications of system dynamics modelling to support health policy. Public Health Res Pract. 2015;25(3):e2531531

46. McKelvie D. Modelling social care complexity: the potential of system dynamics. London: NIHR School for Social Care Research; 2013.

47. Cosenz F, Noto G. Applying system dynamics modelling to strategic management: a literature review. Syst Res Behav Sci. 2016;

48. Shepherd SP. A review of system dynamics models applied in transportation. Transportmetrica B: Transport Dynamics. 2014;2(2):83-105.

49. Rouwette EAJA, JAM V, TV M. Group model building effectiveness: a review of assessment studies. Syst Dyn Rev. 2002;18(1):5-45.

50. Caulfield CW, Ma SP. A case for systems thinking and system dynamics. In: IEEE international conference on systems, man and cybernetics, vol. 2001. USA: Tucson; 2001. p. 2793-8.

51. El Sawah S, McLucas A, Mazanov J. Communication about Water Management in the Australian Capital Territory: A System Dynamics Modelling Approach In: 27th International Conference of the System Dynamics Society: July 26-30 2009. Albuquerque, New Mexico; 2009.

52. Stave KA. Zero waste by 2030: a system dynamics simulation tool for stakeholder involvement in Los Angeles' solid waste planning initiative. In: 26th international conference of the system dynamics society: 20-24 July. Greece: Athens; 2008. p. 2008.

53. Pasqualini D, Witkowski M, Klare P, Patelli P, Cleland C. A Model for a Water Potable Distribution System and its Impacts resulting from a Water Contamination Scenario. In: International Conference of System Dynamics Society. The Netherland; 2006.

\section{Submit your next manuscript to BioMed Central and we will help you at every step:}

- We accept pre-submission inquiries

- Our selector tool helps you to find the most relevant journal

- We provide round the clock customer support

- Convenient online submission

- Thorough peer review

- Inclusion in PubMed and all major indexing services

- Maximum visibility for your research

Submit your manuscript at www.biomedcentral.com/submit 